\title{
O passado irrevogável na justiça de transição
}

\author{
The irrevocable past in transitional justice
}

BEVERNAGE, Berber. History, memory and state-sponsored violence: time and justice. New York/London: Routledge, 2011, 250 p.

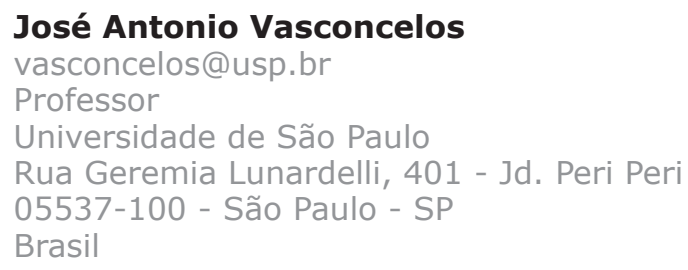

Palavras-chave

História do tempo presente; Memória coletiva; Tempo histórico.

Keywords

History of present time; Collective memory; Historical time. 
Berber Bevernage é atualmente pesquisador pós-doutorando na Universidade de Ghent, na Bélgica. Nesta mesma universidade defendeu uma tese de doutorado que foi publicada com o título de History, memory and state-sponsored violence. Numa passada rápida de olhos pelo sumário, e a julgar pelo título da obra, poderíamos ser levados a crer que é antes de tudo um livro sobre a justiça de transição e o estabelecimento de "comissões da verdade". A atualidade e importância dessa discussão são particularmente evidentes no cenário político brasileiro atual, já que um órgão dessa natureza foi oficialmente instalado em maio de 2012 e encontra-se assim em plena atividade. Porém, embora o livro descreva e comente com certo nível de profundidade três contextos de justiça de transição - as Madres de Plaza de Mayo, na Argentina, o legado do Apartheid na África do Sul, e os dilemas do período pós-revolucionário em Serra Leoa - estes não constituem o foco da obra, mas são tomados como instâncias a partir das quais Bevernage desenvolve algo mais fundamental: uma teoria da história fundada no conceito de passado irrevogável (irrevocable past).

Esse conceito, na verdade, remete à obra do filósofo francês Vladimir Jankélévitch acerca da temporalidade e de nossa relação com o passado. À irreversibilidade do passado, isto é, a uma experiência do passado como algo que não pode ser reatualizado e tampouco alterado, Jankélévitch opõe o passado irrevogável, um passado que de alguma forma permanece no presente e do qual não podemos nos desvencilhar por um simples ato da vontade. Bevernage 306 relaciona o primeiro tipo de experiência à história, enquanto o segundo seria pressuposto pelo direito.

Exemplo de irrevogabilidade do passado seria a responsabilidade imputada a criminosos: um crime ainda não prescrito constitui uma ação que tomou lugar no passado, mas dele decorre uma culpa que permanece no presente, e que só pode se tornar pretérita sob a condição de que seu autor seja trazido à justiça e cumpra a pena devida. Trata-se, é claro, de uma concepção de justiça como um sistema de trocas, alvo de inúmeras e consistentes críticas, mas que, não obstante, serve a Bevernage como uma maneira possível de se pensar a questão do tempo em relação à jurisprudência. Esse é o caso de levantes revolucionários que, quando vitoriosos, estabelecem tribunais para julgar e punir os responsáveis por abusos do regime que foi derrubado. Trata-se de ações no presente que visam estabelecer um corte temporal que possa eliminar ou ao menos reduzir uma perturbadora presença do passado no presente.

Porém, lembra Bevernage, na maioria das vezes, nas nações que se tornaram democráticas depois de um período de governo autoritário, a democracia foi conquistada em grande parte a partir de processos de negociação. Nesses casos as instituições democráticas se estabelecem geralmente com a ressalva de que os que ocupavam posição de mando no regime anterior não sofram represálias, que seus crimes sejam perdoados e esquecidos. Anistia e amnésia social seriam as duas faces da mesma moeda. Essa fórmula, contudo, não se dá sem um flagrante paradoxo: 
Porque esses dois imperativos [justiça e reconciliação] frequentemente parecem opostos, os comentadores têm falado de uma "escolha do diabo" ou um "dilema da justiça transicional": reparar a injustiça histórica e assim assumir o risco da discórdia social, desestabilização e retorno da violência; ou almejar um presente e futuro democráticos e pacíficos para a "desvantagem" das vítimas de um passado sombrio? (BEVERNAGE 2012, p. 7).

Nem mesmo a passagem do tempo, necessária para o trabalho do luto e superação das memórias traumáticas, seria suficiente, segundo Bevernage, para dar conta desse paradoxo. Para justificar essa afirmação, ele se remete a Michael Ignatieff, historiador e político canadense, segundo o qual "os crimes jamais podem ser seguramente fixados no passado: eles permanecem num presente eterno clamando por vingança" (IGNATIEFF apud BEVERNAGE 2012, p. 13). Evidência disso, de acordo com Ignatieff, seriam as referências que a Guerra Civil Iugoslava teria feito a conflitos anteriores, que datariam de 1841, 1841 ou mesmo 1441. Acrescentando outros exemplos, Bevernage argumenta que estaríamos vivendo num novo regime d'historicité, para usar o conhecido conceito de François Hartog, e que uma nova consciência histórica estaria promovendo cada vez mais a permanência de memórias traumáticas.

Diante do impasse entre justiça e reconciliação, e convicto de que a mera passagem do tempo não é capaz de solucionar esse dilema, Bevernage considera o estabelecimento de comissões de verdade como uma terceira via: seu papel seria o de fazer com que a sociedade assumisse um compromisso de que os crimes do passado não fossem esquecidos, sem que isso resultasse necessariamente na punição dos criminosos. Trata-se da possibilidade de uma anistia "anamnestética", isto é, de uma reconciliação que reconheça as injustiças praticadas no passado, mas que ao mesmo tempo opere um corte entre o presente e o passado, de modo essas injustiças pretéritas não permaneçam "assombrando" (haunting) o presente e comprometendo o futuro. Em outras palavras, trata-se de substituir o passado irrevogável da jurisprudência pelo passado irreversível da história. "Essa perspectiva", afirma Bevernage,

nos permite apreender uma dimensão da história que excede sua função tradicional de representar o passado, procurar a verdade ou gerar significado. Em relação a uma modernidade ameaçada pelo irrevogável, a história é útil por uma propriedade [...] que é frequentemente negligenciada: a de regular a distância temporal (BEVERNAGE 2012, p. 15).

Contudo, se em tese as comissões de verdade se apresentam em princípio como uma alternativa viável para a aporia justiça/reconciliação, na prática a superação de um passado irrevogável revela ser um empreendimento por vezes irrealizável. É esse o caso, por exemplo, da resistência ao luto, e consequentemente à perlaboração dele decorrente, manifestada no movimento das Madres de Plaza de Mayo, com seu slogan "Aparición con vida". Nesse sentido as Madres repudiam não somente a relativa impunidade das juntas militares, como também os trabalhos da Comissión Nacional sobre la Desaparición de 
Personas, especialmente pelo propósito desta em dar um "fechamento" à questão. Disso Bevernage conclui que a

a recusa das Madres em desempenhar o trabalho de luto, sua resistência ao fechamento, e sua alegação de que desaparecidos fantasmagóricos jamais serão um assunto do passado constitui um ataque frontal às concepções modernas predominantes de tempo e história (BEVERNAGE 2012, p. 45).

Essa dicotomia entre a tese de um papel "redentor" da verdade histórica e a persistência do passado irrevogável na memória coletiva é ainda mais evidente no contexto da Truth and Reconciliation Comission (TRC), a comissão da verdade estabelecida na África do Sul entre 1996 e 2006. A TRC repercutiu no cenário internacional tanto como "uma inovação legal quanto uma solução para os duros dilemas envolvidos no trato com o passado doloroso de situações pós-guerra" (BEVERNAGE 2012, p. 46). Mas essa aparente "história de sucesso" no cenário internacional é também alvo de inúmeras críticas, especialmente em âmbito doméstico. Em primeiro lugar, os trabalhos da comissão enfrentaram constrangimentos legais e políticos que tornaram a publicação dos resultados muito menos reveladora do que o esperado. Na prática, efetuou-se apenas o reconhecimento oficial daquilo que já havia sido bastante explorado pela mídia e que àquela altura havia se tornado quase senso-comum. Em segundo lugar, o TRC "usava de um lado uma linguagem estritamente positivista, e de outro às 308 vezes alargava seu conceito de verdade de modo a incluir verdades pessoais, sociais, curativas e restaurativas, que geralmente são estranhas aos historiadores profissionais" (BEVERNAGE 2012, p. 55). Aliás, é sintomática a ausência de historiadores entre os membros da Comissão da Verdade e Reconciliação sul-africana. Além disso, há questionamentos acerca da legitimidade de uma comissão que "perdoa" criminosos sem incorporar nesse processo a participação de sobreviventes da violência e de familiares das vítimas.

Em seguida Bevernage apresenta o caso de Serra Leoa. Ali o estabelecimento de uma comissão da verdade, após um período de guerra civil que se estendeu de 1991 a 2002, apresenta dificuldades e paradoxos ainda maiores em comparação com as comissões homólogas na Argentina e na África do Sul, tendo em vista a realização de um projeto de justiça de transição e da superação de um passado irrevogável.

Em primeiro lugar há de se considerar a fragilidade do acordo de paz de Lomé, assinado em julho de 1999, que já previa a criação de uma comissão da verdade. Como ainda persistiam tensões que podiam reacender o conflito, os trabalhos da comissão eram vistos com suspeita pela população de Serra Leoa, pois se temia que a lembrança das atrocidades cometidas, mesmo sob a forma de um "passado irreversível da história", despertasse animosidades latentes. Em segundo lugar, a atuação conjunta de uma instância jurídica com poder punitivo, o Tribunal Especial para Serra Leoa, criava um contexto no qual, em determinadas situações, a Comissão de Verdade e Reconciliação passava ser vista como uma paródia do primeiro, isso sem mencionar o fato de que muitas 
testemunhas tinham o receio de que seus depoimentos na comissão fossem utilizados para incriminá-los no tribunal. Em terceiro lugar, as atividades da Comissão de Verdade e Reconciliação de Serra Leoa envolviam em diversas ocasiões uma relação bastante direta com rituais religiosos de inspiração animista, de modo que a proposta de superação do passado irrevogável se fazia de forma bastante ambígua, a meio caminho entre o mito e a história. É importante notar que, tal como a comissão sul-africana, a comissão de Serra Leoa não tinha historiadores entre seus integrantes. E finalmente, e talvez o mais importante, é que a Comissão de Verdade e Reconciliação de Serra Leoa desenvolvia seus trabalhos sem estar em sintonia com as expectativas das vítimas e sobreviventes. De acordo com Bevernage:

A necessidade de ajuda financeira ou compensação material obviamente era a razão para que muitas vítimas e sobreviventes se dirigissem à comissão. Ao fim de quase todos os testemunhos perguntava-se aos membros da comissão o que eles planejavam fazer para mudar o estado de contínua escassez das vítimas. Geralmente os membros da comissão reagiam a estas questões argumentando que o ganho do testemunho é psicológico, que a comissão ajuda a assegurar que o passado nunca retorne, que sua missão é ajudar as comunidades mais que os indivíduos, e que o progresso da nação é o mais importante (BEVERNAGE 2012, p. 78).

Além utilizar um tom paternalista, ao final dos trabalhos, os membros da comissão solicitavam às vítimas que "esquecessem o passado", um grande paradoxo, considerando que o objetivo primordial de um órgão dessa natureza seria exatamente o da reconciliação por meio do reconhecimento da verdade e da criação de um registro histórico. Afinal, não seriam tarefas da comissão reverter e/ou prevenir a injustiça ocasionada pela anistia associada à amnésia social?

O trabalho de Bevernage traz uma contribuição significativa não só aos debates sobre teoria da história, como também aos estudos sociológicos da memória, em especial por sua problematização do tempo e da relação entre o passado e o presente na historiografia e na memória social. No campo da teoria da história é possível associar a obra de Bevernage a estudos como os de François Hartog, que problematiza a questão do tempo histórico, ou de Henry Rousso, que tematiza a história do tempo presente. Mas Bevernage estabelece estreitos laços também com a sociologia, remetendo-se, como seria de esperar, ao conceito de memória coletiva de Maurice Halbwachs, mas também a autores mais recentes, como Yosef Yerushalmi, que trata da tensão entre história e memória na representação judaica do passado, ou Jeff Olick, que evidencia a emergência de uma política do arrependimento, enfatizando a atual importância do reconhecimento coletivo dos erros pretéritos como condição para um "acerto de contas" com o passado.

A originalidade de Bevernage em relação às demais obras que tratam do entrecruzamento entre tempo, história e memória reside em seu uso do conceito de passado irrevogável para entender os contextos de justiça de transição. Nesse sentido, History, memory and state-sponsored violence constitui um importante modelo de investigação, pois articula permanentemente 
os conceitos que apresenta e desenvolve a situações históricas particulares. Assim, a argumentação teórica se torna mais didática e, ao mesmo tempo, mais consistente. Esse modo de argumentação traz a vantagem adicional de ser mais atraente a historiadores que reclamam do caráter excessivamente abstrato de muitas das pesquisas no campo da teoria da história.

A despeito de seus méritos, que não são poucos nem pequenos, a obra de Bevernage apresenta, senão insuficiências, ao menos alguns aspectos incongruentes com a proposta geral de sua tese. Até aproximadamente metade do livro o autor desenvolve uma reflexão sobre a relação entre os conceitos de "passado irrevogável" e "passado irreversível" a partir da análise dos trabalhos de comissões da verdade em diferentes países. Mas, numa segunda parte, o livro assume um tom mais didático, elucidando conceitos - historicismo, modernismo e secularismo - e discutindo autores - Braudel, Collingwood, Ernst Bloch, Althusser, Freud, Gennep e Derrida - , tudo isso de forma bastante esquemática, para ao fim justificar sua preferência teórica pela abordagem desconstrucionista e pós-estruturalista de Derrida. Mas, se é assim, porque as ideias de Derrida não foram incorporadas à discussão sobre os contextos de justiça de transição e comissões da verdade? Ou por que, após argumentar em favor da desconstrução derridiana, Bevernage não remete o leitor novamente às Madres da Argentina ou às comissões da verdade e reconciliação da África do Sul e de Serra Leoa, relendo essas instâncias de justiça de transição à luz de Spectres de Marx ou Mémoires - pour Paul de Man?

310 Bevernage salienta que os contextos de justiça de transição possibilitam pensar a história de modo muito pouco convencional, pois, enquanto os historiadores acadêmicos em geral estudam o passado para salvá-lo do esquecimento, as comissões da verdade produziriam conhecimento histórico como uma forma de estabelecer um corte ou distanciamento em relação a um passado lembrado em demasia.

Mas será mesmo que a representação do passado realizada ou pelo menos almejada pelas comissões da verdade pode ser chamada de história? Sem ambiguidade? Se é sensato afirmar que "a memória manifesta uma estrutura temporal radicalmente diferente daquela da historiografia acadêmica" (BEVERNAGE 2012, p. 14), isso não torna necessária a tese de que toda representação que pretenda um corte ou distanciamento em relação ao passado seja historiográfica. A pesquisa acadêmica demanda, além de determinada estrutura temporal, uma série de pressupostos teóricos e metodológicos de modo que as questões possam ser partilhadas e debatidas no âmbito de uma argumentação lógico-conceitual, e só nesse sentido é pertinente chamá-la de História como categoria distinta da memória. Os resultados dos trabalhos das comissões da verdade, priorizando aspectos éticos e políticos em detrimento do rigor conceitual e, como no caso de Serra Leoa, invocando "espíritos dos mortos", pertencem ao domínio da memória social, mas não da história propriamente dita.

Uma última questão, que se coloca não tanto como crítica às ideias de Bervernage, mas como sugestão de avanço sobre suas reflexões, tem a ver com a tese da "permanência" do passado irrevogável. Se é inegável que 
eventos traumáticos permaneçam na memória social por um período difícil de determinar, deve-se levar também em consideração que as lembranças desses eventos podem ser continuamente reatualizadas e até mesmo reinventadas em função de fatores atuando no presente. Em outras palavras, o trauma associado à representação de uma experiência de violência no passado pode, como pensa Bevernage, se remeter a um passado irrevogável que se estende continuamente da experiência passada ao presente vivido. Mas pode se tratar também de uma representação traumática inventada no presente e que toma como referente um acontecimento passado, ainda que não exista uma continuidade entre ambos. Para utilizar um exemplo do próprio Bevernage, será que a referência da Guerra Civil Iugoslava às campanhas militares de 1441 implica na permanência de uma memória coletiva ou na ressignificação de um contexto histórico do passado à luz das experiências vividas no presente? E essa insistência do passado em não passar, essa resistência à perlaboração que Bevernage identifica no mundo contemporâneo, será que não se trata aí também de uma contínua reinvenção e ressignificação do passado a cada novo presente, muito mais do que a permanência de um passado irrevogável?

De um modo geral o livro de Bevernage é resultado de uma pesquisa extensa e competente, que se apresenta na forma de uma argumentação inteligente e estimulante. Nesse sentido, se há na obra aspectos incongruentes ou insuficientemente desenvolvidos, como os esboçados acima, isso se dá principalmente em função do amplo escopo da pesquisa. Sem dúvida se trata de uma contribuição importante para os atuais estudos em teoria da história, se afastando dos temas mais frequentemente explorados, como objetividade, cientificidade ou narrativa, mas ao mesmo tempo criando e/ou problematizando novos conceitos, articulando-os a contextos históricos específicos e remetendo-se a autores e ideias fundamentais na área. 